London, for lending us the equipment to perform resections and outpatient hysteroscopy; Dr Elizabeth Horak, clinical lecturer in the Nuffield department of pathology, Oxford, for performing the histological examinations; Mr J C Smith, consultant urologist, Oxford, for his invaluable advice and enthusiastic support of our work; and the Wellington Foundation for its financial help to ALM to attend the hysteroscopy course and workshop at the Jan Palfjin Hospital in Antwerp, Belgium.

1 Rybo G. Clinical and experimental studies on menstrual blood loss. Acta Obste Gynecol Scand 1966;45(suppl): 1-23.

2 Chimbira TH, Anderson ABM. Turnbull AC. Relation between measured menstrual blood loss and patien's subjective assessment of loss, duration of derigent bleeding, number of sanitary towels used, uterine

Rees MP. Menorrhagia - an algorithm. Br Med f 1987;294:759-62.

3 Rees MP. Menorrhagia - an algorithm. Br Med F 1987;294:759-62.

5 Dicker RC, Scally MJ, Greenspan JR, et al. Hysterectomy among women of reproductive age. Trends in the United States, 1970-1978. JAMA 1982;248:
reter reprodict

6 DeCherney AH, Polan ML. Hysteroscopic management of intrauterine lesions and intractable uterine bleeding. Obstet Gynecol 1983;61:392-7.

7 DeCherney AH, Diamond MP, Lavy G, Polan ML. Endometrial ablation fo intractable uterine bleeding: hysteroscopic resection. Obstet Gynecol 1987;70:668-70

8 Zipper J, Medel M, Pastene L, Rivera M. Intrauterine instillation of chemical cytotoxic agents for tubal sterilisation and treatment of functional metrorrhagias. Int $\mathcal{F}$ Fertil 1969;14:280-8.

9 Droegemueller W, Makowski E, Macsalka R. Destruction of the endometrium by cryosurgery. Am $\mathcal{F}$ Obstet Gynecol 1971;110:467-9.

10 Goldrath MH, Fuller TA, Segal S. Laser photovaporisation of endometrium for the treatment of menorrhagia. Am $\mathcal{F}$ Obstet Gynecol 1981;140:14-9.

11 Cornier E. Traitement hysterofibroscopique ambulatoire des metrorragies rebelles par laser Nd:YAG. I Gynecol Obstet Biol Reprod (Paris) 1986;15: 661.4

12 Baggish MS, Baltoyannis P. New techniques for laser ablation in high-risk patients. Am $\mathcal{F}$ Obstet Gynecol 1988;159:287-92.
13 Neuwirth RS. A new technique for and additional experience with hysteroscopic resection of submucous fibroids. Am $f$ Obstet Gymecol 1978;131:91-4

14 Haning RV, Harkins PG, Uehling DT. Preservation of fertility by transcervical resection of a benign mesodermal uterine tumor with a resectoscope and ection of a benign mesoderril

15 DeCherney AN, Russell JB, Graebe RA, Polan ML. Resectoscopic management of mullerian fusion defects. Fertil Steril 1986;45:726-8.

16 Loffer FD. Laser ablation of the endometrium. Obstet Gynecol Clin North Am 988;15:77-89.

17 Haynes PJ, Hodgson H, Anderson ABM, Turnbull AC. Measurement of menstrual blood loss in patients complaining of menorrhagia. $\mathrm{Br}$ f Obstet Gynaecol 1977;84:763-8.

18 Schenker JG, Polishuk WZ. Regeneration of rabbit endometrium following intrauterine instillation of chemical agents. Gynecol Invest 1973;4:1-13.

19 Asherman JG. Traumatic intra-uterine adhesions. Fournal of Obstetrics and Gynaecology of the British Empire 1950;57:892-903.

20 Department of Health and Social Security and Office of Population Censuses and Surveys. Hospital in-patient enquiry, 1985. London: HMSO, 1985: table P1. (MB No 4.)

21 Grant JM, Hussein IY. An audit of abdominal hysterectomy over a decade in a district hospital. Br f Obstet Gynaecol 1984;91:73-7.

22 Wingo PA, Huezo CM, Rubin GL, Ory HW, Peterson HB. The mortality risk associated with hysterectomy. Am $\mathcal{O}$ Obstet Gynecol 1985;152:803-8.

23 Dicker RC, Greenspan JR, Strauss LT, et al. Complications of abdominal and vaginal hysterectomy among women of reproductive age in the United States. Am J Obstet Gynecol 1982;144:841-8.

24 Siddle N, Sarrel $P$, Whitehead MI. The effect of hysterectomy on the age of ovarian failure: identification of a subgroup of women with premature loss of ovarian function and literature review. Fertil Steril 1987;47:94-100.

25 Centerwall BS. Premenopausal hysterectomy and cardiovascular disease. $A m \mathcal{F}$ Obstet Gynecol 1981;139:58-61.

26 Richards DH. A post-hysterectomy syndrome. Lancet 1974;ii:983-5.

27 Baggish MS, Woodruff JD. The occurrence of squamous epithelium in the endometrium. Obstet Gynecol Surv 1967;22:69-115.

28 Rioux JE. Methods of uterine distension. In: Seigler AL, Lindemann HJ, eds. Hysteroscopy: principles and practice. Philadelphia: Lippincott, 1984:37-40.

(Accepted 28 March 1989)
Epidemiology and Public Health Research Unit, University of Surrey, Guildford, Surrey GU2 5XH

P Yuen, MSC, research fellow R Balarajan, FFCM, director

Correspondence to:

Dr Balarajan.

\title{
Unemployment and patterns of consultation with the general practitioner
}

\author{
P Yuen, R Balarajan
}

\begin{abstract}
The relation between unemployment and consultations with the general practitioner was investigated among 13275 economically active men aged 18-64 by using the British general household surveys. Men who were unemployed but seeking work consulted with doctors significantly more (odds ratio $1.83 ; 95 \%$ confidence interval 1.61 to 2.09 ) than those in employment, the highest consultation rate being among those who had been out of work for five years or more (odds ratio $2 \cdot 12 ; 95 \%$ confidence interval 1.12 to 3.78 ). The high consultation rates persisted even after adjustment for self reported longstanding illness (odds ratio 1.53; 95\% confidence interval 1.34 to $1 \cdot 76)$.
\end{abstract}

These findings suggest that in areas with high unemployment general practitioner workload is likely to be high.

\section{Introduction}

Unemployment in Britain rose rapidly in the early 1980 s, a fivefold increase having occurred over 12 years. ${ }^{1}$ This increase focused a great deal of interest on the health of the unemployed. In England and Wales excess mortality among unemployed men seeking work has been shown by using data from the Office of Population Censuses and Surveys' longitudinal study, the excess mortality persisting even when socioeconomic factors such as social class and housing tenure were taken into account. ${ }^{23} \mathrm{~A}$ follow up study in Denmark also disclosed significantly higher death rates among the unemployed. ${ }^{4}$ Nevertheless, little published research has been made available on the levels and patterns of morbidity among those out of work. Small scale observational studies have reported high levels of stress and mental disorders in those unemployed and those under threat of becoming unemployed. ${ }^{56}$ Most of these studies were not representative, being either too small or localised, with the exception of the recent Canada health survey. ${ }^{7}$ In that study substantial differences in health between the employed and unemployed were found, people out of work having significantly higher levels of psychological stress and ill health.

We have analysed data from the British general household surveys to investigate the health of the unemployed as it relates to consultation with a general practitioner.

\section{Subjects and methods}

The general household survey is a yearly sample survey conducted by the Office of Population Censuses and Surveys, providing information on a wide range of topics such as employment, health, housing, and education in some 30000 people from 12000 private households. The 1983 and 1984 surveys $^{89}$ were combined and used in this analysis to increase the sample size. We defined as unemployed people who were not working but were seeking work or waiting to take up a job and included in our study only economically active men aged 18 to 64 . Full time students and those who were permanently sick and unable to work were excluded. Duration of unemployment was further examined in five categories (table I).

To allow for possible confounding we also obtained information on age, housing tenure, occupation (most 
recent job for those seeking work), and geographical regions (table I). Standard regions of Britain were aggregated into five broad regions based on the distribution of unemployment.

Consultation with a general practitioner was defined as contact up to 14 days before the interview. This included speaking to the doctor on the telephone as well as the doctor seeing the patient at home or in the surgery for medical reasons.

Multiple logistic regression was used to model the probability of consultation with respect to employment state, allowing for age, socioeconomic group, housing tenure, and geographical region. ${ }^{10}$ The general household survey also collects information on self reported morbidity, covering longstanding illness or infirmity or disability that affects daily activity. Thirty per cent of the total study sample was reportedly suffering from longstanding illness. Though we excluded from our study men who were unable to take up employment because of illness and those who were permanently sick, we also controlled for the presence of longstanding illness by repeating the modelling by including it as one of the explanatory variables. The statistical package generalised linear interactive modelling (GLIM) was used for the analysis." A simultaneous testing procedure was used to scan for possible interactions that should be included in the model. ${ }^{12}$ Preliminary modelling showed no significant interactions among the explanatory variables for consultation with a general practitioner. Maximum likelihood estimates of the odds ratios and their standard errors for employment state were therefore derived from the main effects models and were adjusted for age, socioeconomic group, housing tenure, and region of residence. Approximate $95 \%$ confidence intervals were then calculated.

\section{Results}

The study comprised 13275 men aged 18-64 who were economically active. Table II shows their distribution of employment state by age, socioeconomic group, housing tenure, and region of residence. Altogether 1592 (12\%) of the men had been seeking work in the week before the interview. Twenty one per cent (477/2251) of men aged 18-24 were out of work compared with $8 \%(254 / 3253)$ of those aged $35-44$ Among the socioeconomic groups semiskilled and unskilled manual workers accounted for the highest proportions out of work (20\% (420/2083) and 34\% (194/579) respectively). Twenty six per cent of men living in council properties (837/3271) were unemployed compared with only $6 \%(559 / 8741)$ in the owner occupier group. A geographical variation in unemployment was also evident. The south east and London had lower levels of unemployment (7\% (294/

TABLE I-Grouping of explanatory variables as used in statistical models

\begin{tabular}{|c|c|}
\hline Explanatory variable & Explanatory variable \\
\hline $\begin{array}{l}\text { Duration of unemployment: } \\
\text { (1) Employed } \\
\text { (2) Unemployed less than } 3 \text { months } \\
\text { (3) Unemployed for } 3 \text { months or more } \\
\text { but less than } 1 \text { year } \\
\text { (4) Unemployed for } 1 \text { year or more but } \\
\text { less than } 2 \text { years } \\
\text { (5) Unemployed for } 2 \text { years or more but } \\
\text { less than } 5 \text { years } \\
\text { (6) Unemployed for } 5 \text { years or more }\end{array}$ & $\begin{array}{l}\text { Age (years): } \\
\text { (1) } 18-24 \\
\text { (2) } 25-34 \\
\text { (3) } 35-44 \\
\text { (4) } 45-54 \\
\text { (5) } 55-64 \\
\text { Housing tenure: } \\
\text { (1) Owner occupier } \\
\text { (2) Council tenant } \\
\text { (3) Private tenant }\end{array}$ \\
\hline $\begin{array}{l}\text { Socioeconomic group: } \\
\text { (1) Professional/managers/employers } \\
\text { (2) Intermediate junior non-manual } \\
\text { (3) Skilled manual } \\
\text { (4) Semiskilled manual } \\
\text { (5) Unskilled manual }\end{array}$ & $\begin{array}{l}\text { Region of residence: } \\
\text { (1) South east (excluding } \\
\text { London) } \\
\text { (2) Central } \\
\text { (3) North } \\
\text { (4) London } \\
\text { (5) Scotland }\end{array}$ \\
\hline
\end{tabular}

TABLE II-Distribution of employment state stratified by age, socioeconomic group, housing tenure, and region of residence among men aged 18-64. (General household surveys 1983, 1984.) Figures are numbers (percentages) of men

\begin{tabular}{|c|c|c|c|}
\hline & Employed & Unemployed & Total \\
\hline $\begin{array}{c}\text { Age (years): } \\
18-24 \\
25-34 \\
35-44 \\
45-54 \\
55-64\end{array}$ & $\begin{array}{l}1774(79) \\
2883(88) \\
2999(92) \\
2325(91) \\
1702(87)\end{array}$ & $\begin{array}{l}477(21) \\
386(12) \\
254(8) \\
218(9) \\
257(13)\end{array}$ & $\begin{array}{l}2251(100) \\
3269(100) \\
3253(100) \\
2543(100) \\
1959(100)\end{array}$ \\
\hline Total & $11683(88)$ & $1592(12)$ & $13275(100)$ \\
\hline
\end{tabular}

Socioeconomic group: $\begin{array}{llll} & 2936(97) & 105(3) & 3041(100)\end{array}$

Skilled manual

Unskilled manual $\begin{array}{lll}2033(94) & 140(6) & 2173(100) \\ 4555(88) & 614(12) & 5169(100)\end{array}$

Tota $385(66) \quad 194(34) \quad 579(100)$

$11572(89) \quad 1473(11) \quad 13045(100)^{\star}$

Housing tenure:

Owner occupier $\quad 8182(94) \quad 559(6) \quad 8741(100)$

$\begin{array}{lrll}\text { Council tenant } & 2434(74) & 837(26) & 3271(100) \\ \text { Private tenant } & 993(85) & 180(15) & 1173(100)\end{array}$

Total

$11609(88) \quad 1576(12) \quad 13185(100)^{\star}$

Region of residence:

South east (excluding London) $\quad 3786(93) \quad 294(7) \quad 4080(100)$

$\begin{array}{llll}\text { Central } & 2969(86) & 476(14) & 3445(100)\end{array}$

North

London

Scotland

$2484(85) \quad 455(15) \quad 2939(100)$

$\begin{array}{lll}1356(89) & 173(11) & 1529(100) \\ 1088(85) & 194(15) & 1282(100)\end{array}$

Total

$11683(88) \quad 1592(12) \quad 13275(100)$

*Data missing in some cases.

TABLE III-Distribution of duration of unemployment stratified by age among economically active men aged 18-64. Figures are numbers (percentages) of men

\begin{tabular}{lrrrc}
\hline & \multicolumn{4}{c}{ Duration of unemployment (years) } \\
\cline { 2 - 5 } Age (years) & \multicolumn{1}{c}{$<1$} & \multicolumn{1}{c}{$1-$} & $\geqslant 2$ & Total \\
\hline $18-24$ & $258(54)$ & $119(25)$ & $100(21)$ & $477(100)$ \\
$25-34$ & $170(44)$ & $89(23)$ & $127(33)$ & $386(100)$ \\
$35-44$ & $97(38)$ & $53(21)$ & $104(41)$ & $254(100)$ \\
$45-54$ & $85(39)$ & $37(17)$ & $96(44)$ & $218(100)$ \\
$55-64$ & $100(39)$ & $44(17)$ & $113(44)$ & $257(100)$ \\
\hline Total & $710(45)$ & $342(21)$ & $540(34)$ & $1592(100)$ \\
& & & & \\
\hline
\end{tabular}

TABLE IV-Adjusted odds ratios for consultation with a genera practitioner among men aged 18-64

\begin{tabular}{lcc}
\hline Employment state & Odds ratio $^{\star}$ & $95 \%$ Confidence interval \\
\hline Employed & 1.00 & - \\
Unemployed & 1.83 & 1.61 to 2.09
\end{tabular}

*Odds ratios adjusted for age, socioeconomic group, housing tenure, and region of residence.

$4080)$ and $11 \%(173 / 1529)$ respectively) than the rest of Britain, the highest level being in the North $(15.5 \%$ (455/2939)).

Table III shows the duration of unemployment stratified by age. Over half of those who were unemployed had been out of work for more than a year, and $34 \%(540 / 1592)$ had been unemployed for more than two years. As expected, short term unemployment was found mainly among the younger age groups, whereas long term unemployment affected mainly the older age groups. Among men aged 45-64 who were out of work, 44\% (209/475) had been seeking work for more than two years.

After adjustment for age, housing tenure, socioeconomic group, and region of residence men who were unemployed but seeking work had a significantly higher odds ratio than those in employment for consultation with a general practitioner (odds ratio $1 \cdot 83 ; 95 \%$ confidence interval 1.61 to $2 \cdot 09$ ) (table IV). 
The effect of length of unemployment on the patterns of consultation with a doctor was investigated by categorising the duration into five groups (figure). No significant gradient was detected, though men who had been out of work for five years or more had a substantially higher odds ratio than other men for consultation (odds ratio $2 \cdot 12 ; 95 \%$ confidence interval $1 \cdot 12$ to $3 \cdot 78)$.

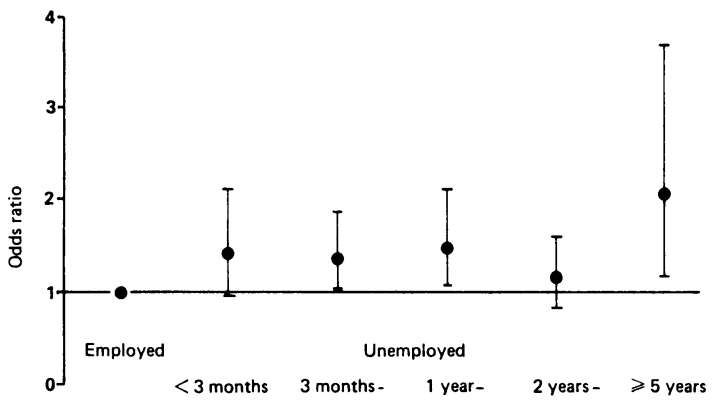

Adjusted odds ratios (points) and $95 \%$ confidence intervals (bars) for consultation with a general practitioner among men aged 18-64 stratified by duration of unemployment. (Odds ratios adjusted for age, housing tenure, socioeconomic group, and region)

When the presence of longstanding illness was included as an explanatory variable in the model the adjusted odds ratio remained significantly high among those unemployed, though to a lesser extent (odds ratio $1 \cdot 53 ; 95 \%$ confidence interval $1 \cdot 34$ to $1 \cdot 76$ ) (table V).

TABLE $\mathrm{v}-$ Adjusted odds ratios for consultation with a general practitioner among men aged 18-64 including longstanding illness as explanatory variable

\begin{tabular}{lcc}
\hline & Odds ratio $^{\star}$ & $95 \%$ Confidence interval \\
\hline Employment state: & 1.00 & - \\
$\quad$ Employed & 1.53 & 1.34 to 1.76 \\
Unemployed & 1.00 & - \\
Longstanding illness: & 2.91 & 2.59 to 3.27 \\
$\quad$ No &
\end{tabular}

^Odds ratios adjusted for age, socioeconomic group, housing tenure, and region of residence.

Men who reported longstanding illness and had been out of work had an odds ratio of 4.5 after adjustment for age, area of residence, housing tenure, and socioeconomic group.

\section{Discussion}

The general household survey, though not specially designed to investigate issues relating to unemployment, provided relevant information on employment state, health, and other sociodemographic characteristics of a representative sample of men living in private households in Great Britain. This enabled us to link unemployment state and sociodemographic variables to health outcome at the primary care level. The general household survey, however, did not cover people in institutions and in other residential accommodation. The level of unemployment $(12 \%)$ among the economically active men from the 1983 and 1984 surveys was representative of the level of unemployment in Britain. This contrasts with the 4\% recorded as unemployed in the Office of Population Censuses and Surveys' longitudinal study ${ }^{2}{ }^{3}$ and the $1 \%$ recorded as unemployed in the Danish longitudinal study. ${ }^{4}$

Patterns of consultation with the general practi- tioner are also associated with people's socioeconomic and demographic characteristics, ${ }^{13-15}$ so necessitating the inclusion of such confounding variables in the examination of the health of the unemployed. We have shown a strong association between consultation with the general practitioner and unemployment independent of such factors.

Studying the health of the unemployed based on a cross sectional survey such as the general household survey does not provide the opportunity to investigate the causal pathway - that is, whether unemployment causes a deterioration in health or whether unemployment is a sequel to poor health. Though we excluded men who were permanently sick and included only those actually seeking work, possibly some whose unemployment was a consequence of ill health were included. Unemployed men, however, consulted their general practitioner significantly more than those in employment (odds ratio 1.53) even after adjustment for self reported long standing illness. Though duration of unemployment did not show an obvious gradient in consultation, men who had been out of work for five years or more had a substantially higher adjusted odds ratio $(2 \cdot 12)$.

Our results, which correspond with other local studies in Britain ${ }^{5}$ and the findings of the Canada health survey, ${ }^{7}$ are further evidence of the association between unemployment and the uptake of primary care. In areas where rates of unemployment are high the workload of general practitioners is likely to be higher and the nature of the clinical presentations may be such that they require more than the average consultation time. These consultations are likely to require more counselling in matters for which some general practitioners may find themselves less equipped. Managing the health of the unemployed may be difficult for the profession given that prevention is not in the hands of the practitioners themselves but more in the sociopolitical arena.

We are grateful to the Office of Population Censuses and Surveys and the Economic and Social Research Council Data Archive for making available the general household survey data for this study.

1 Smith R. A doctor's guide to the facts and figures of unemployment. Br Med $\mathcal{J}$

$1985 ; 291: 1107-11$.
2 Moser KA, Fox AJ, Jones DR. Unemployment and mortality in the OPCS longitudinal study. Lancet 1984;ii:1324-8.

3 Moser KA, Fox AJ, Jones DR, Goldblatt PO. Unemployment and mortality: Moser KA, Fox AJ, Jones DR, Goldblatt PO. Unemployment and mortality:
further evidence from the OPCS longitudinal study 1971-81. Lancet further evidence

4 Iversen L, Andersen O, Andersen PK, Christoffersen K, Keiding N. Unemployment and mortality in Denmark, 1970-80. Br Med $\mathcal{J} 1987 ; 295$ : 879-84.

5 Beale N, Nethercott S. Job loss and family morbidity: a study of a factory closure. F R Coll Gen Pract 1985;35:510-4.

6 Kessler RC. Unemployment and health in a community sample. $\mathcal{f}$ Health Soc Behav 1987;147:51-9.

7 D'Arcy C. Unemployment and health: data and implications. Can $\mathcal{F}$ Public Health 1986;77(suppl): 124-31.

8 Office of Population Censuses and Surveys. General household survey 1983. London: HMSO, 1985.

9 Office of Population Censuses and Surveys. General household survey 1984. London: HMSO, 1986.

10 Cox DR. Analysis of binary data. London: Chapman and Hall, 1972

11 Baker RJ, Nelder JA. GLIM system (3.77). Oxford: Numerical Algorithms Group, 1985.

12 Aitkin M. A note on the selection of log linear models. Biometrics 1980;36: 173-8.

13 Balarajan R, Yuen P, Machin D. Socioeconomic differentials in the uptake of medical care in Great Britain. I Epidemiol Community Health 1987;41:196-9. 14 Balarajan R, Yuen P, Machin D. Socioeconomic differentials in health status: their application in health care planning and resource allocation. Surrey: Epidemiology and Public Health Research Unit, University of Surrey, 1987. 5 Balarajan R, Yuen P, Machin D. Socioeconomic differentials in health status: their application in health care planning and resource allocation. Second report. Surrey: Epidemiology and Public Health Research Unit, University of Surrey, 1987.

(Accepted 24 February 1989) 